\title{
Common coupled fixed point theorems for Geraghty-type contraction mappings using monotone property
}

Zoran Kadelburg ${ }^{1}$, Poom Kumam²,3* Stojan Radenović ${ }^{4}$ and Wutiphol Sintunavarat ${ }^{5 *}$

\author{
"Correspondence: \\ poom.kum@kmutt.ac.th; \\ wutiphol@mathstat.sci.tu.ac.th: \\ poom_teun@hotmail.com \\ ${ }^{2}$ Department of Mathematics, \\ Faculty of Science, King Mongkut's \\ University of Technology Thonburi, \\ 126 Pracha Uthit Road, Bang Mod, \\ Thung Khru, Bangkok, 10140, \\ Thailand \\ ${ }^{5}$ Department of Mathematics and \\ Statistics, Faculty of Science and \\ Technology, Thammasat University, \\ Rangsit Center, Pathumthani, 12121, \\ Thailand \\ Full list of author information is \\ available at the end of the article
}

\begin{abstract}
In this paper, we prove common coupled fixed point theorems under a Geraghty-type condition using monotone instead of the often used mixed monotone property. Also we give some sufficient conditions for the uniqueness of a common coupled fixed point. An example illustrating our results is provided. MSC: $47 \mathrm{H} 10 ; 54 \mathrm{H} 25$

Keywords: partially ordered metric space; coupled fixed point; mixed monotone property; Geraghty-type condition
\end{abstract}

\section{Introduction}

As the Banach contraction principle (BCP) is a power tool for solving many problems in applied mathematics and sciences, it has been improved and extended in many ways. In particular, Geraghty proved in 1973 [1] an interesting generalization of BCP which has had a lot of applications.

The notion of a coupled fixed point was firstly introduced and studied by Opoitsev [2, 3] and then by Guo and Lakshmikantham in [4]. In 2006, Bhaskar and Lakshmikantham [5] were the first to introduce the notion of mixed monotone property. They also studied and proved the following classical coupled fixed point theorems for mappings by using this property under contractive type conditions.

Theorem 1.1 ([5]) Let $(X, d, \preceq)$ be a partially ordered complete metric space and let $F$ : $X \times X \rightarrow X$ be a continuous mapping having the mixed monotone property, i.e., for any $x, y \in X$,

$$
x_{1}, x_{2} \in X, \quad x_{1} \preceq x_{2} \quad \Rightarrow \quad F\left(x_{1}, y\right) \preceq F\left(x_{2}, y\right)
$$

and

$$
y_{1}, y_{2} \in X, \quad y_{1} \preceq y_{2} \quad \Rightarrow \quad F\left(x, y_{1}\right) \succeq F\left(x, y_{2}\right)
$$

hold. Assume that there exists $k \in[0,1)$ such that

$$
d(F(x, y), F(u, v)) \leq \frac{k}{2}[d(x, u)+d(y, v)]
$$


holds for all $x, y, u, v \in X$ with $x \succeq u$ and $y \preceq v$. If there exist $x_{0}, y_{0} \in X$ such that

$$
x_{0} \preceq F\left(x_{0}, y_{0}\right), \quad y_{0} \succeq F\left(y_{0}, x_{0}\right),
$$

then there exist $x, y \in X$ such that $x=F(x, y)$ and $y=F(y, x)$, i.e., $F$ has a coupled fixed point.

Theorem 1.2 ([5]) If the continuity assumption for the mapping $F$ is replaced by the assumption that the space $(X, d, \preceq)$ has the following properties:

1. if $\left\{x_{n}\right\}$ is a non-decreasing sequence with $\left\{x_{n}\right\} \rightarrow x$, then $x_{n} \leq x$ for all $n \geq 1$,

2. if $\left\{y_{n}\right\}$ is a non-increasing sequence with $\left\{y_{n}\right\} \rightarrow y$, then $y_{n} \succeq y$ for all $n \geq 1$.

Then the same conclusion as in the previous theorem holds.

Due to the important role of Theorems 1.1 and 1.2 for the investigation of solutions of nonlinear differential and integral equations, several authors have studied various generalizations of these results (see, e.g., papers [6-18] and the references cited therein). Almost all of them used the mixed monotone property or, in the case of additional mapping $g: X \rightarrow X$, the so-called $g$-mixed monotone property.

Recently, in [19-21], the author established common coupled fixed point theorems by using $(g$-)monotone property instead of $(g$-)mixed monotone property. These kinds of results can be applied in another type of situations, so they give an opportunity to widen the field of applications. In particular the so-called tripled fixed point results (and, more generally, $n$-tupled results) can be more easily handled using monotone property instead of mixed monotone property (see, e.g., [22-24]).

The aim of this work is to prove some common coupled fixed point theorems for Geraghty-type contraction mappings by using monotone and $g$-monotone property instead of mixed monotone and $g$-mixed monotone property. An illustrative example is presented in this work showing how our results can be used in proving the existence of a common coupled fixed point, while the results of many other papers cannot.

\section{Preliminaries}

In this section, we give some definitions that are useful for our main results in this paper. Throughout this paper $(X, \preceq)$ denotes a partially ordered set. By $x \succeq y$, we mean $y \preceq x$. Let $f, g: X \rightarrow X$ be mappings. A mapping $f$ is said to be $g$-non-decreasing (resp., $g$-nonincreasing) if, for all $x, y \in X, g x \preceq g y$ implies $f x \preceq f y$ (resp., $f y \preceq f x$ ). If $g$ is an identity mapping, then $f$ is said to be non-decreasing (resp., non-increasing).

Definition 2.1 Let $(X, \preceq)$ be a partially ordered set and let $F: X \times X \rightarrow X$ and $g: X \rightarrow X$ be two mappings. The mapping $F$ is said to have the $g$-monotone property if $F$ is monotone $g$-non-decreasing in both of its arguments, that is, for any $x, y \in X$,

$$
x_{1}, x_{2} \in X, \quad g x_{1} \preceq g x_{2} \quad \Rightarrow \quad F\left(x_{1}, y\right) \preceq F\left(x_{2}, y\right)
$$

and

$$
y_{1}, y_{2} \in X, \quad g y_{1} \preceq g y_{2} \quad \Rightarrow \quad F\left(x, y_{1}\right) \preceq F\left(x, y_{2}\right)
$$

hold. If in the previous relations $g$ is the identity mapping, then $F$ is said to have the monotone property. 
Definition $2.2([5,12])$ Let $X$ be a nonempty set and $F: X \times X \rightarrow X, g: X \rightarrow X$ be two mappings. An element $(x, y) \in X \times X$ is called:

$\left(C_{1}\right)$ a coupled fixed point of $F$ if $x=F(x, y)$ and $y=F(y, x)$;

$\left(\mathrm{C}_{2}\right)$ a coupled coincidence point of mappings $g$ and $F$ if

$$
g x=F(x, y) \quad \text { and } \quad g y=F(y, x)
$$

and in this case $(g x, g y)$ is called a coupled point of coincidence;

$\left(\mathrm{C}_{3}\right)$ a common coupled fixed point of mappings $g$ and $F$ if

$$
x=g x=F(x, y) \quad \text { and } \quad y=g y=F(y, x)
$$

Definition 2.3 ([25]) Let $(X, d)$ be a metric space and let $g: X \rightarrow X, F: X \times X \rightarrow X$. The mappings $g$ and $F$ are said to be compatible if

$$
\lim _{n \rightarrow \infty} d\left(g F\left(x_{n}, y_{n}\right), F\left(g x_{n}, g y_{n}\right)\right)=0 \quad \text { and } \quad \lim _{n \rightarrow \infty} d\left(g F\left(y_{n}, x_{n}\right), F\left(g y_{n}, g x_{n}\right)\right)=0
$$

hold whenever $\left\{x_{n}\right\}$ and $\left\{y_{n}\right\}$ are sequences in $X$ such that $\lim _{n \rightarrow \infty} F\left(x_{n}, y_{n}\right)=\lim _{n \rightarrow \infty} g x_{n}$ and $\lim _{n \rightarrow \infty} F\left(y_{n}, x_{n}\right)=\lim _{n \rightarrow \infty} g y_{n}$.

\section{Main results}

Let $\Theta$ denote the class of all functions $\theta:[0, \infty) \times[0, \infty) \rightarrow[0,1)$ which satisfy the following conditions:

$\left(\theta_{1}\right) \quad \theta(s, t)=\theta(t, s)$ for all $s, t \in[0, \infty)$;

$\left(\theta_{2}\right)$ for any two sequences $\left\{s_{n}\right\}$ and $\left\{t_{n}\right\}$ of nonnegative real numbers,

$$
\theta\left(s_{n}, t_{n}\right) \rightarrow 1 \quad \Rightarrow \quad s_{n}, t_{n} \rightarrow 0
$$

The following are examples of some functions belonging to $\Theta$.

(1) $\theta(s, t)=k$ for $s, t \in[0, \infty)$, where $k \in[0,1)$.

(2) $\theta(s, t)=\left\{\begin{array}{ll}\frac{\ln (1+k s+t t)}{k s+t t}, & s>0 \text { or } t>0, \\ r \in[0,1), & s=0, t=0,\end{array}\right.$ where $k, l \in(0,1)$.

(3) $\theta(s, t)= \begin{cases}\frac{\ln (1+\max \{s, t))}{\max \{s, t\}}, & s>0 \text { or } t>0, \\ r \in[0,1), & s=0, t=0 .\end{cases}$

Now, we will prove our main result.

Theorem 3.1 Let $(X, d, \preceq)$ be a complete partially ordered metric space and let $g: X \rightarrow X$ and $F: X \times X \rightarrow X$ be such that $F$ has the $g$-monotone property. Suppose that the following hold:

(i) $g$ is continuous and $g(X)$ is closed;

(ii) $F(X \times X) \subset g(X)$ and $g$ and $F$ are compatible;

(iii) there exist $x_{0}, y_{0} \in X$ such that $g x_{0} \preceq F\left(x_{0}, y_{0}\right)$ and $g y_{0} \preceq F\left(y_{0}, x_{0}\right)$;

(iv) there exists $\theta \in \Theta$ such that for all $x, y, u, v \in X$ satisfying $g x \preceq$ gu and $g y \preceq g v$ or $g x \geq g u$ and $g y \geq g \nu$,

$$
d(F(x, y), F(u, v)) \leq \theta(d(g x, g u), d(g y, g v)) \max \{d(g x, g u), d(g y, g v)\}
$$


(v) (a) $F$ is continuous or (b) if, for an increasing sequence $\left\{x_{n}\right\}$ in $X, x_{n} \rightarrow x \in X$ as $n \rightarrow \infty$, then $x_{n} \preceq x$ for all $n \in \mathbb{N}$.

Then there exist $u, v \in X$ such that $g u=F(u, v)$ and $g v=F(v, u)$, i.e., $g$ and $F$ have a coupled coincidence point.

Proof Starting from $x_{0}, y_{0}$ (condition (iii)) and using that $F(X \times X) \subset g(X)$ (condition (ii)), we can construct sequences $\left\{x_{n}\right\}$ and $\left\{y_{n}\right\}$ in $X$ such that

$$
g x_{n}=F\left(x_{n-1}, y_{n-1}\right) \quad \text { and } \quad g y_{n}=F\left(y_{n-1}, x_{n-1}\right) \quad \text { for } n=1,2, \ldots
$$

If $g x_{n_{0}}=g x_{n_{0}-1}$ and $g y_{n_{0}}=g y_{n_{0}-1}$ for some $n_{0} \in \mathbb{N}$, then $\left(g x_{n_{0}-1}, g y_{n_{0}-1}\right)$ is a coupled point of coincidence for $g$ and $F$. Therefore, in what follows, we will assume that for each $n \in \mathbb{N}$, $g x_{n} \neq g x_{n-1}$ or $g y_{n} \neq g y_{n-1}$ holds.

By (iii), $g x_{0} \preceq F\left(x_{0}, y_{0}\right)=g x_{1}$ and $g y_{0} \preceq F\left(y_{0}, x_{0}\right)=g y_{1}$, hence the $g$-monotone property of $F$ implies that $g x_{1}=F\left(x_{0}, y_{0}\right) \preceq F\left(x_{1}, y_{1}\right)=g x_{2}$ and $g y_{1}=F\left(y_{0}, x_{0}\right) \preceq F\left(y_{1}, x_{1}\right)=g y_{2}$. Proceeding by induction we get that $g x_{n-1} \preceq g x_{n}$ and $g y_{n-1} \preceq g y_{n}$ hold for each $n \in \mathbb{N}$. Hence, the contractive condition (3.1) can be used to conclude that

$$
\begin{aligned}
d\left(g x_{n}, g x_{n+1}\right) & =d\left(F\left(x_{n-1}, y_{n-1}\right), F\left(x_{n}, y_{n}\right)\right) \\
& \leq \theta\left(d\left(g x_{n-1}, g x_{n}\right), d\left(g y_{n-1}, g y_{n}\right)\right) \max \left\{d\left(g x_{n-1}, g x_{n}\right), d\left(g y_{n-1}, g y_{n}\right)\right\}
\end{aligned}
$$

and

$$
\begin{aligned}
d\left(g y_{n}, g y_{n+1}\right) & =d\left(F\left(y_{n-1}, x_{n-1}\right), F\left(y_{n}, x_{n}\right)\right) \\
& \leq \theta\left(d\left(g y_{n-1}, g y_{n}\right), d\left(g x_{n-1}, g x_{n}\right)\right) \max \left\{d\left(g y_{n-1}, g y_{n}\right), d\left(g x_{n-1}, g x_{n}\right)\right\} \\
& =\theta\left(d\left(g x_{n-1}, g x_{n}\right), d\left(g y_{n-1}, g y_{n}\right)\right) \max \left\{d\left(g x_{n-1}, g x_{n}\right), d\left(g y_{n-1}, g y_{n}\right)\right\}
\end{aligned}
$$

for all $n \in \mathbb{N}$. From (3.2) and (3.3), we get

$$
\begin{aligned}
& \max \left\{d\left(g x_{n}, g x_{n+1}\right), d\left(g y_{n}, g y_{n+1}\right)\right\} \\
& \quad \leq \theta\left(d\left(g x_{n-1}, g x_{n}\right), d\left(g y_{n-1}, g y_{n}\right)\right) \max \left\{d\left(g x_{n-1}, g x_{n}\right), d\left(g y_{n-1}, g y_{n}\right)\right\} \\
& \quad \leq \max \left\{d\left(g x_{n-1}, g x_{n}\right), d\left(g y_{n-1}, g y_{n}\right)\right\}
\end{aligned}
$$

for all $n \in \mathbb{N}$. Thus the sequence $d_{n}:=\max \left\{d\left(g x_{n-1}, g x_{n}\right), d\left(g y_{n-1}, g y_{n}\right)\right\}$ is decreasing. It follows that $d_{n} \rightarrow d$ as $n \rightarrow \infty$ for some $d \geq 0$. Next, we claim that $d=0$.

Assume on the contrary that $d>0$; then from (3.4) we obtain that

$$
\frac{\max \left\{d\left(g x_{n}, g x_{n+1}\right), d\left(g y_{n}, g y_{n+1}\right)\right\}}{\max \left\{d\left(g x_{n-1}, g x_{n}\right), d\left(g y_{n-1}, g y_{n}\right)\right\}} \leq \theta\left(d\left(g x_{n-1}, g x_{n}\right), d\left(g y_{n-1}, g y_{n}\right)\right)<1 .
$$

On taking limit as $n \rightarrow \infty$, we get

$$
\theta\left(d\left(g x_{n-1}, g x_{n}\right), d\left(g y_{n-1}, g y_{n}\right)\right) \rightarrow 1 \quad \text { as } n \rightarrow \infty .
$$

Since $\theta \in \Theta$, we have

$$
d\left(g x_{n-1}, g x_{n}\right) \rightarrow 0 \quad \text { and } \quad d\left(g y_{n-1}, g y_{n}\right) \rightarrow 0
$$


as $n \rightarrow \infty$ and hence

$$
d_{n}=\max \left\{d\left(g x_{n-1}, g x_{n}\right), d\left(g y_{n-1}, g y_{n}\right)\right\} \rightarrow 0 \quad \text { as } n \rightarrow \infty
$$

which contradicts the assumption $d>0$. Therefore, we can conclude that $d_{n}=\max \left\{d\left(g x_{n-1}\right.\right.$, $\left.\left.g x_{n}\right), d\left(g y_{n-1}, g y_{n}\right)\right\} \rightarrow 0$ as $n \rightarrow \infty$.

Next, we show that $\left\{g x_{n}\right\}$ and $\left\{g y_{n}\right\}$ are Cauchy sequences. On the contrary, assume that at least one of $\left\{g x_{n}\right\}$ or $\left\{g y_{n}\right\}$ is not a Cauchy sequence. Then there is $\epsilon>0$ for which we can find subsequences $\left\{g x_{n_{k}}\right\},\left\{g x_{m_{k}}\right\}$ of $\left\{g x_{n}\right\}$ and $\left\{g y_{n_{k}}\right\},\left\{g y_{m_{k}}\right\}$ of $\left\{g y_{n}\right\}$ with $n_{k}>m_{k} \geq k$ such that

$$
\max \left\{d\left(g x_{n_{k}}, g x_{m_{k}}\right), d\left(g y_{n_{k}}, g y_{m_{k}}\right)\right\} \geq \epsilon
$$

and

$$
\max \left\{d\left(g x_{n_{k}-1}, g x_{m_{k}}\right), d\left(g y_{n_{k}-1}, g y_{m_{k}}\right)\right\}<\epsilon .
$$

Using (3.6), (3.7) and the triangle inequality, we have

$$
\begin{aligned}
\epsilon & \leq r_{k}:=\max \left\{d\left(g x_{n_{k}}, g x_{m_{k}}\right), d\left(g y_{n_{k}}, g y_{m_{k}}\right)\right\} \\
& \leq \max \left\{d\left(g x_{n_{k}}, g x_{n_{k}-1}\right), d\left(g y_{n_{k}}, g y_{n_{k}-1}\right)\right\}+\max \left\{d\left(g x_{n_{k}-1}, g x_{m_{k}}\right), d\left(g y_{n_{k}-1}, g y_{m_{k}}\right)\right\} \\
& <\max \left\{d\left(g x_{n_{k}}, g x_{n_{k}-1}\right), d\left(g y_{n_{k}}, g y_{n_{k}-1}\right)\right\}+\epsilon .
\end{aligned}
$$

On taking limit as $k \rightarrow \infty$, we have

$$
r_{k}=\max \left\{d\left(g x_{n_{k}}, g x_{m_{k}}\right), d\left(g y_{n_{k}}, g y_{m_{k}}\right)\right\} \rightarrow \epsilon
$$

By the triangle inequality, we get

$$
\begin{aligned}
r_{k}= & \max \left\{d\left(g x_{n_{k}}, g x_{m_{k}}\right), d\left(g y_{n_{k}}, g y_{m_{k}}\right)\right\} \\
\leq & \max \left\{d\left(g x_{n_{k}}, g x_{n_{k}+1}\right), d\left(g y_{n_{k}}, g y_{n_{k}+1}\right)\right\}+\max \left\{d\left(g x_{n_{k}+1}, g x_{m_{k}+1}\right), d\left(g y_{n_{k}+1}, g y_{m_{k}+1}\right)\right\} \\
& +\max \left\{d\left(g x_{m_{k}+1}, g x_{m_{k}}\right), d\left(g y_{m_{k}+1}, g y_{m_{k}}\right)\right\} \\
= & \max \left\{d\left(g x_{n_{k}}, g x_{n_{k}+1}\right), d\left(g y_{n_{k}}, g y_{n_{k}+1}\right)\right\}+\max \left\{d\left(g x_{m_{k}+1}, g x_{m_{k}}\right), d\left(g y_{m_{k}+1}, g y_{m_{k}}\right)\right\} \\
& +\max \left\{d\left(g x_{n_{k}+1}, g x_{m_{k}+1}\right), d\left(g y_{n_{k}+1}, g y_{m_{k}+1}\right)\right\} \\
\leq & \max \left\{d\left(g x_{n_{k}}, g x_{n_{k}+1}\right), d\left(g y_{n_{k}}, g y_{n_{k}+1}\right)\right\}+\max \left\{d\left(g x_{m_{k}+1}, g x_{m_{k}}\right), d\left(g y_{m_{k}+1}, g y_{m_{k}}\right)\right\} \\
& +\theta\left(d\left(g x_{n_{k}}, g x_{m_{k}}\right), d\left(g y_{n_{k}}, g y_{m_{k}}\right)\right) \max \left\{d\left(g x_{n_{k}}, g x_{m_{k}}\right), d\left(g y_{n_{k}}, g y_{m_{k}}\right)\right\} \\
= & d_{n_{k}+1}+d_{m_{k}+1}+\theta\left(d\left(g x_{n_{k}}, g x_{m_{k}}\right), d\left(g y_{n_{k}}, g y_{m_{k}}\right)\right) r_{k} \\
\leq & d_{n_{k}+1}+d_{m_{k}+1}+r_{k}
\end{aligned}
$$

(the usage of contractive condition (3.1) was possible since the sequences $\left\{g x_{n}\right\}$ and $\left\{g y_{n}\right\}$ are increasing). Now, we have

$$
r_{k} \leq d_{n_{k}+1}+d_{m_{k}+1}+\theta\left(d\left(g x_{n_{k}}, g x_{m_{k}}\right), d\left(g y_{n_{k}}, g y_{m_{k}}\right)\right) r_{k} \leq d_{n_{k}+1}+d_{m_{k}+1}+r_{k} .
$$


On taking limit as $k \rightarrow \infty$ and using (3.5) and (3.8), we get

$$
\theta\left(d\left(g x_{n_{k}}, g x_{m_{k}}\right), d\left(g y_{n_{k}}, g y_{m_{k}}\right)\right) \rightarrow 1
$$

Using the properties of function $\theta$, we obtain

$$
d\left(g x_{n_{k}}, g x_{m_{k}}\right) \rightarrow 0 \quad \text { and } \quad d\left(g y_{n_{k}}, g y_{m_{k}}\right) \rightarrow 0
$$

as $k \rightarrow \infty$, which imply that

$$
\lim _{k \rightarrow \infty} r_{k}=\lim _{k \rightarrow \infty}\left(\max \left\{d\left(g x_{n_{k}}, g x_{m_{k}}\right), d\left(g y_{n_{k}}, g y_{m_{k}}\right)\right\}\right)=0,
$$

which contradicts with $\epsilon>0$.

Therefore, we get that $\left\{g x_{n}\right\}$ and $\left\{g y_{n}\right\}$ are Cauchy sequences. Since $g(X)$ is a closed subset of a complete metric space, there exist $u, v \in g(X)$ such that

$$
\lim _{n \rightarrow \infty} g x_{n}=\lim _{n \rightarrow \infty} F\left(x_{n}, y_{n}\right)=u \text { and } \lim _{n \rightarrow \infty} g y_{n}=\lim _{n \rightarrow \infty} F\left(y_{n}, x_{n}\right)=v .
$$

By condition (ii), the compatibility of $g$ and $F$ implies that

$$
\lim _{n \rightarrow \infty} d\left(g F\left(x_{n}, y_{n}\right), F\left(g x_{n}, g y_{n}\right)\right)=0 \quad \text { and } \quad \lim _{n \rightarrow \infty} d\left(g F\left(y_{n}, x_{n}\right), F\left(g y_{n}, g x_{n}\right)\right)=0 .
$$

Consider the two possibilities given in condition (v).

(a) Suppose that $F$ is continuous. Using the triangle inequality we get that

$$
d\left(g u, F\left(g x_{n}, g y_{n}\right)\right) \leq d\left(g u, g F\left(x_{n}, y_{n}\right)\right)+d\left(g F\left(x_{n}, y_{n}\right), F\left(g x_{n}, g y_{n}\right)\right) .
$$

Passing to the limit as $n \rightarrow \infty$ and using (3.9) and the continuity of $g$ and $F$, we get that $d(g u, F(u, v))=0$, i.e., $g u=F(u, v)$. In a similar way, $g v=F(v, u)$ is obtained.

(b) In this case $g x_{n} \preceq u=g x$ and $g y_{n} \preceq v=g y$ for some $x, y \in X$ and each $n \in \mathbb{N}$. Using (3.1) we get

$$
\begin{aligned}
d(F(x, y), g x) & \leq d\left(F(x, y), g x_{n+1}\right)+d\left(g x_{n+1}, g x\right) \\
& =d\left(F(x, y), F\left(x_{n}, y_{n}\right)\right)+d\left(g x_{n+1}, g x\right) \\
& \leq \theta\left(d\left(g x, g x_{n}\right), d\left(g y, g y_{n}\right)\right) \max \left\{d\left(g x, g x_{n}\right), d\left(g y, g y_{n}\right)\right\}+d\left(g x_{n+1}, g x\right) \\
& \rightarrow 0
\end{aligned}
$$

as $n \rightarrow \infty$. Hence, $g x=F(x, y)$ and similarly $g y=F(y, x)$.

Note that in this case continuity and compatibility assumptions were not needed in the proof.

Remark 3.2 In Theorem 3.1, the condition that $F$ has the $g$-monotone property is a substitution for the $g$-mixed monotone property that was used in most of the coupled fixed point results so far. Note that this condition is maybe more natural than the mixed $g$-monotone property and can be used in various examples. 
Putting $g=I_{X}$, where $I_{X}$ is an identity mapping on $X$ in Theorem 3.1, we obtain the following.

Corollary 3.3 Let $(X, d, \preceq)$ be a partially ordered complete metric space and let $F: X \times$ $X \rightarrow X$ have the monotone property. Suppose that the following hold:

(i) there exist $x_{0}, y_{0} \in X$ such that $x_{0} \preceq F\left(x_{0}, y_{0}\right)$ and $y_{0} \preceq F\left(y_{0}, x_{0}\right)$;

(ii) there exists $\theta \in \Theta$ such that for all $x, y, u, v \in X$ satisfying ( $x \preceq u$ and $y \preceq v)$ or $(u \preceq x$ and $v \preceq y$ ),

$$
d(F(x, y), F(u, v)) \leq \theta(d(x, u), d(y, v)) \max \{d(x, u), d(y, v)\}
$$

holds true;

(iii) (a) $F$ is continuous or (b) if $\left\{x_{n}\right\}$ is an increasing sequence in $X$ and $x_{n} \rightarrow x$ as $n \rightarrow \infty$, then $x_{n} \preceq x$ for all $n$.

Then there exist $x, y \in X$ such that $x=F(x, y)$ and $y=F(y, x)$, i.e., $F$ has a coupled fixed point.

Taking $\theta\left(t_{1}, t_{2}\right)=k$ with $k \in[0,1)$ for all $t_{1}, t_{2} \in[0, \infty)$ in Theorem 3.1 and Corollary 3.3, we obtain the following corollary.

Corollary 3.4 Let $(X, d, \preceq)$ be a complete partially ordered metric space and let $g: X \rightarrow X$ and $F: X \times X \rightarrow X$ be such that $F$ has the $g$-monotone property. Suppose that the following hold:

(i) $g$ is continuous and $g(X)$ is closed;

(ii) $F(X \times X) \subset g(X)$ and $g$ and $F$ are compatible;

(iii) there exist $x_{0}, y_{0} \in X$ such that $g x_{0} \preceq F\left(x_{0}, y_{0}\right)$ and $g y_{0} \preceq F\left(y_{0}, x_{0}\right)$;

(iv) there exists $k \in[0,1)$ such that for all $x, y, u, v \in X$ satisfying ( $g x \preceq g u$ and $g y \preceq g v$ ) or ( $g u \preceq g x$ and $g \nu \preceq g y)$,

$$
d(F(x, y), F(u, v)) \leq k \max \{d(g x, g u), d(g y, g v)\}
$$

holds true;

(v) (a) $F$ is continuous or (b) if $\left\{x_{n}\right\}$ is an increasing sequence in $X$ and $x_{n} \rightarrow x$ as $n \rightarrow \infty$, then $x_{n} \preceq x$ for all $n$.

Then there exist $u, v \in X$ such that $g u=F(u, v)$ and $g v=F(v, u)$, i.e., $g$ and $F$ have a coupled coincidence point.

Corollary 3.5 Let $(X, d, \preceq)$ be a partially ordered complete metric space and let $F: X \times$ $X \rightarrow X$. Suppose that the following hold:

(i) F satisfies the monotone property;

(ii) there exist $x_{0}, y_{0} \in X$ such that $x_{0} \preceq F\left(x_{0}, y_{0}\right)$ and $y_{0} \preceq F\left(y_{0}, x_{0}\right)$;

(iii) there exists $k \in[0,1)$ such that for all $x, y, u, v \in X$ satisfying ( $x \preceq u$ and $y \preceq v$ ) or $(u \preceq x$ and $v \preceq y$ ),

$$
d(F(x, y), F(u, v)) \leq k \max \{d(x, u), d(y, v)\}
$$


(iv) (a) $F$ is continuous or (b) if $\left\{x_{n}\right\}$ is an increasing sequence in $X$ and $x_{n} \rightarrow x$ as $n \rightarrow \infty$, then $x_{n} \preceq x$ for all $n$.

Then there exist $x, y \in X$ such that $x=F(x, y)$ and $y=F(y, x)$, i.e., $F$ has a coupled fixed point.

Remark 3.6 Since, for $k, l \geq 0, k+l \leq 1$,

$$
k d(g x, g u)+l d(g y, g v) \leq \max \{d(g x, g u), d(g y, g v)\}
$$

Corollary 3.4 remains valid if the right-hand side of condition (3.10) is replaced by $k d(g x$, $g u)+l d(g y, g v)$ for some $k, l \geq 0, k+l<1$.

Now, reasoning on Theorem 3.1, some questions arise naturally. To be precise, one can ask the following.

Question Is it possible to find a sufficient condition for the existence and uniqueness of the coupled common fixed point of $g$ and $F$ ?

Motivated by the interest in this research, we give a positive answer to this question adding to Theorem 3.1 some hypotheses.

For the given partial order $\preceq$ on the set $X$, we shall denote also by $\preceq$ the order on $X \times X$ given by

$$
\left(x_{1}, y_{1}\right) \preceq\left(x_{2}, y_{2}\right) \quad \Leftrightarrow \quad x_{1} \preceq x_{2} \quad \text { and } \quad y_{1} \preceq y_{2} \text {. }
$$

Theorem 3.7 In addition to the hypotheses of Theorem 3.1 assume that

(vi) for any two elements $(x, y),(u, v) \in X \times X$, there exists $(w, z) \in X \times X$ such that $(F(w, z), F(z, w))$ is comparable to both $(F(x, y), F(y, x))$ and $(F(u, v), F(v, u))$.

Then $g$ and $F$ have a unique common coupled fixed point, i.e., there exists unique $(p, q) \in$ $X \times X$ such that $p=g p=F(p, q)$ and $q=g q=F(q, p)$.

Proof Theorem 3.1 implies that there exists a coupled coincidence point $(x, y) \in X \times X$, that is, $g x=F(x, y)$ and $g y=F(y, x)$. Suppose that there exists another coupled coincidence point $(u, v) \in X \times X$ and hence $g u=F(u, v)$ and $g v=F(v, u)$. We will prove that $g x=g u$ and $g y=g \nu$.

From condition (vi) we get that there exists $(w, z) \in X \times X$ such that $(F(w, z), F(z, w))$ is comparable to both $(F(x, y), F(y, x))$ and $(F(u, v), F(v, u))$. Put $w_{0}=w, z_{0}=z$ and, analogously to the proof of Theorem 3.1 , choose sequences $\left\{w_{n}\right\},\left\{z_{n}\right\}$ in $X$ satisfying

$$
g w_{n}=F\left(w_{n-1}, z_{n-1}\right) \quad \text { and } \quad g z_{n}=F\left(z_{n-1}, w_{n-1}\right)
$$

for $n \in \mathbb{N}$. Starting from $x_{0}=x, y_{0}=y$ and $u_{0}=u, v_{0}=v$, choose sequences $\left\{x_{n}\right\},\left\{y_{n}\right\}$ and $\left\{u_{n}\right\},\left\{v_{n}\right\}$ satisfying $g x_{n}=F\left(x_{n-1}, y_{n-1}\right), g y_{n}=F\left(y_{n-1}, x_{n-1}\right)$ and $g u_{n}=F\left(u_{n-1}, v_{n-1}\right), g v_{n}=$ $F\left(v_{n-1}, u_{n-1}\right)$ for $n \in \mathbb{N}$. Taking into account the properties of coincidence points, it is easy to see that it can be done so that $x_{n}=x, y_{n}=y$ and $u_{n}=u, v_{n}=v$, i.e.,

$$
g x_{n}=F(x, y), \quad g y_{n}=F(y, x) \quad \text { and } \quad g u_{n}=F(u, v), \quad g v_{n}=F(v, u) \quad \text { for all } n \in \mathbb{N} \text {. }
$$


Since $(F(x, y), F(y, x))=(g x, g y)$ and $(F(w, z), F(z, v))=\left(g w_{1}, g z_{1}\right)$ are comparable, then, for example, $g x \preceq g w_{1}, g y \preceq g z_{1}$ and in a similar way, $g x \preceq g w_{n}, g y \preceq g z_{n}$. Thus, we can apply the contractive condition (3.1) to obtain

$$
\begin{aligned}
d\left(g x, g w_{n+1}\right) & =d\left(F(x, y), F\left(w_{n}, z_{n}\right)\right) \\
& \leq \theta\left(d\left(g x, g w_{n}\right), d\left(g y, g z_{n}\right)\right) \max \left\{d\left(g x, g w_{n}\right), d\left(g y, g z_{n}\right)\right\}
\end{aligned}
$$

and

$$
\begin{aligned}
d\left(g y, g z_{n+1}\right) & =d\left(F\left(z_{n}, w_{n}\right), F(y, x)\right) \\
& \leq \theta\left(d\left(g y, g z_{n}\right), d\left(g x, g w_{n}\right)\right) \max \left\{d\left(g y, g z_{n}\right), d\left(g x, g w_{n}\right)\right\} \\
& =\theta\left(d\left(g x, g w_{n}\right), d\left(g y, g z_{n}\right)\right) \max \left\{d\left(g x, g w_{n}\right), d\left(g y, g z_{n}\right)\right\} .
\end{aligned}
$$

This implies that

$$
\begin{aligned}
& \max \left\{d\left(g x, g w_{n+1}\right), d\left(g y, g z_{n+1}\right)\right\} \\
& \quad \leq \theta\left(d\left(g x, g w_{n}\right), d\left(g y, g z_{n}\right)\right) \max \left\{d\left(g x, g w_{n}\right), d\left(g y, g z_{n}\right)\right\} \\
& \quad<\max \left\{d\left(g x, g w_{n}\right), d\left(g y, g z_{n}\right)\right\} .
\end{aligned}
$$

Therefore, we get that the sequence $d_{n}:=\max \left\{d\left(g x, g w_{n}\right), d\left(g y, g z_{n}\right)\right\}$ is decreasing and hence $d_{n} \rightarrow d$ as $n \rightarrow \infty$ for some $d \geq 0$. Now, we prove that $d=0$. Assume to the contrary that $d>0$; then from (3.11) we have

$$
\frac{\max \left\{d\left(g x, g w_{n+1}\right), d\left(g y, g z_{n+1}\right)\right\}}{\max \left\{d\left(g x, g w_{n}\right), d\left(g y, g z_{n}\right)\right\}} \leq \theta\left(d\left(g x, g w_{n}\right), d\left(g y, g z_{n}\right)\right)<1 .
$$

Taking the limit as $n \rightarrow \infty$ in the above inequality, we have

$$
\theta\left(d\left(g x, g w_{n}\right), d\left(g y, g z_{n}\right)\right) \rightarrow 1 \quad \text { as } n \rightarrow \infty .
$$

By the property $\left(\theta_{2}\right)$ of $\theta \in \Theta$, we get

$$
d\left(g x, g w_{n}\right) \rightarrow 0 \quad \text { and } \quad d\left(g y, g z_{n}\right) \rightarrow 0
$$

as $n \rightarrow \infty$. Now we have

$$
d_{n}:=\max \left\{d\left(g x, g w_{n}\right), d\left(g y, g z_{n}\right)\right\} \rightarrow 0 \quad \text { as } n \rightarrow \infty,
$$

which contradicts with $d>0$. Therefore, we conclude that $d_{n}=\max \left\{d\left(g x, g w_{n}\right), d(g y\right.$, $\left.\left.g z_{n}\right)\right\} \rightarrow 0$ as $n \rightarrow \infty$ and then

$$
\lim _{n \rightarrow \infty} d\left(g x, g w_{n}\right)=0 \quad \text { and } \quad \lim _{n \rightarrow \infty} d\left(g y, g z_{n}\right)=0 .
$$

In a similar way, we have

$$
\lim _{n \rightarrow \infty} d\left(g u, g w_{n}\right)=0 \quad \text { and } \quad \lim _{n \rightarrow \infty} d\left(g v, g z_{n}\right)=0 .
$$


By the triangle inequality, we have

$$
d(g x, g u) \leq d\left(g x, g w_{n}\right)+d\left(g w_{n}, g u\right) \quad \text { and } \quad d(g y, g v) \leq d\left(g y, g z_{n}\right)+d\left(g z_{n}, g v\right)
$$

for all $n \in \mathbb{N}$. Taking $n \rightarrow \infty$ in the above two inequalities, we get that $d(g x, g u)=0$ and $d(g y, g v)=0$. Therefore, we have $g x=g u$ and $g y=g \nu$.

Now we let $p:=g x$ and $q:=g y$. Hence we have

$$
g p=g(g x)=g F(x, y) \quad \text { and } \quad g q=g(g y)=g F(y, x) .
$$

By the definition of sequences $\left\{x_{n}\right\}$ and $\left\{y_{n}\right\}$ we have

$$
g x_{n}=F(x, y)=F\left(x_{n-1}, y_{n-1}\right) \quad \text { and } \quad g y_{n}=F(y, x)=F\left(y_{n-1}, x_{n-1}\right)
$$

for all $n \in \mathbb{N}$. So we have

$$
\lim _{n \rightarrow \infty} F\left(x_{n}, y_{n}\right)=\lim _{n \rightarrow \infty} g x_{n}=F(x, y) \text { and } \lim _{n \rightarrow \infty} F\left(y_{n}, x_{n}\right)=\lim _{n \rightarrow \infty} g y_{n}=F(y, x) .
$$

Since $g$ and $F$ are compatible, we have

$$
\lim _{n \rightarrow \infty} d\left(g F\left(x_{n}, y_{n}\right), F\left(g x_{n}, g y_{n}\right)\right)=0,
$$

that is, $g F(x, y)=F(g x, g y)$. Therefore, we get

$$
g p=g F(x, y)=F(g x, g y)=F(p, q)
$$

and in a similar way

$$
g q=g F(y, x)=F(g y, g x)=F(q, p) .
$$

This implies that $(p, q)$ is another coincidence point. By the property we have just proved, it follows that $g p=g x=p$ and $g q=g y=q$. So,

$$
p=g p=F(p, q) \quad \text { and } \quad q=g q=F(q, p)
$$

and $(p, q)$ is a common coupled fixed point of $g$ and $F$. For the uniqueness of the common coupled fixed point, we can proceed easily.

Corollary 3.8 In addition to the hypotheses of Corollary 3.4 assume that

(vi) for any two elements $(x, y),(u, v) \in X \times X$, there exists $(w, z) \in X \times X$ such that $(F(w, z), F(z, w))$ is comparable to both $(F(x, y), F(y, x))$ and $(F(u, v), F(v, u))$.

Then $g$ and $F$ have a unique common coupled fixed point.

Theorem 3.9 In addition to the hypotheses of Corollary 3.3, let the condition (vi) of Theorem 3.7 be satisfied. Then the coupled fixed point of $F$ is unique. Moreover, iffor the terms of sequences $\left\{x_{n}\right\},\left\{y_{n}\right\}$ defined by $x_{n}=F\left(x_{n-1}, y_{n-1}\right)$ and $y_{n}=F\left(x_{n-1}, y_{n-1}\right), x_{n} \preceq y_{n}$ holds for $n$ sufficiently large, then the coupled fixed point of $F$ has the form $(x, x)$. 
Proof We have only to prove the last statement. Suppose that for $n$ sufficiently large, $x_{n} \preceq y_{n}$. Then, by (3.1) (with $g=I_{X}$ ), we get

$$
\begin{aligned}
d\left(x_{n+1}, y_{n+1}\right) & =d\left(F\left(x_{n}, y_{n}\right), F\left(y_{n}, x_{n}\right)\right) \\
& \leq \theta\left(d\left(x_{n}, y_{n}\right), d\left(x_{n}, y_{n}\right)\right) d\left(x_{n}, y_{n}\right) .
\end{aligned}
$$

This implies that

$$
d\left(x_{n+1}, y_{n+1}\right)<d\left(x_{n}, y_{n}\right),
$$

that is, the sequence $d_{n}:=d\left(x_{n}, y_{n}\right)$ is decreasing. Hence $d_{n} \rightarrow d$ as $n \rightarrow \infty$ for some $d \geq 0$. Next, we prove that $d=0$. Assume to the contrary that $d>0$; then from (3.12) we have

$$
\frac{d\left(x_{n+1}, y_{n+1}\right)}{d\left(x_{n}, y_{n}\right)} \leq \theta\left(d\left(x_{n}, y_{n}\right), d\left(x_{n}, y_{n}\right)\right)<1 .
$$

Letting $n \rightarrow \infty$, we get $\theta\left(d\left(x_{n}, y_{n}\right), d\left(x_{n}, y_{n}\right)\right) \rightarrow 1$. Since $\theta \in \Theta$, we have $d\left(x_{n}, y_{n}\right) \rightarrow 0$ as $n \rightarrow \infty$, which contradicts with $d>0$. Therefore, we have $d\left(x_{n}, y_{n}\right) \rightarrow 0$ as $n \rightarrow \infty$.

By the triangle inequality, we have

$$
\begin{aligned}
d(x, y) & \leq d\left(x, x_{n+1}\right)+d\left(x_{n+1}, y_{n+1}\right)+d\left(y_{n+1}, y\right) \\
& =d\left(x, x_{n+1}\right)+d\left(F\left(x_{n}, y_{n}\right), F\left(y_{n}, x_{n}\right)\right)+d\left(y_{n+1}, y\right) \\
& \leq d\left(x, x_{n+1}\right)+\theta\left(d\left(x_{n}, y_{n}\right), d\left(x_{n}, y_{n}\right)\right) d\left(x_{n}, y_{n}\right)+d\left(y_{n+1}, y\right) \\
& <d\left(x, x_{n+1}\right)+d\left(x_{n}, y_{n}\right)+d\left(y_{n+1}, y\right) .
\end{aligned}
$$

Passing to the limit as $n \rightarrow \infty$, since $x_{n} \rightarrow x, y_{n} \rightarrow y$ and $d\left(x_{n}, y_{n}\right) \rightarrow 0$, we get that $d(x, y) \leq$ 0 and thus $x=y$. This completes the proof.

Corollary 3.10 In addition to the hypotheses of Corollary 3.5, let the condition (vi) of Theorem 3.7 be satisfied. Then the coupled fixed point of $F$ is unique. Moreover, iffor the terms of sequences $\left\{x_{n}\right\},\left\{y_{n}\right\}$ defined by $x_{n}=F\left(x_{n-1}, y_{n-1}\right)$ and $y_{n}=F\left(x_{n-1}, y_{n-1}\right), x_{n} \preceq y_{n}$ holds for all $n$, then the coupled fixed point of $F$ has the form $(x, x)$.

Finally, we give an example showing that our theorem can be used when many results in this field cannot.

Example 3.11 Let $X=[0,1] \subseteq \mathbb{R}$ with the usual metric and order. Consider the mappings $g: X \rightarrow X$ and $F: X \times X \rightarrow X$ defined by

$$
g x=x^{2}, \quad F(x, y)=\ln \left(1+\frac{x^{2}}{2}+\frac{y^{2}}{2}\right) .
$$

Note that $F$ does not satisfy the mixed $g$-monotone property of [25] and [12]. Indeed, for $y_{1}=\frac{1}{3} \in X$ and $y_{2}=\frac{1}{2} \in X$, we have $g y_{1} \preceq g y_{2}$. But for $x=0 \in X$, we get

$$
F\left(x, y_{1}\right)=\ln \frac{19}{18} \preceq \ln \frac{9}{8}=F\left(x, y_{2}\right) .
$$


Hence a lot of results in literature that used the $g$-mixed monotone property cannot be applied in this example. Moreover, $g$ and $F$ do not commute as in [12].

Next, we show that Theorem 3.7 can be used in this example.

Let $\theta \in \Theta$ be defined by

$$
\theta(s, t)= \begin{cases}\frac{\ln \left(1+\frac{s}{2}+\frac{t}{2}\right)}{\frac{s}{2}+\frac{t}{2}}, & s>0 \text { or } t>0, \\ 0, & s=0 \text { and } t=0 .\end{cases}
$$

We will show that condition (3.1) holds with the function $\theta$. Let $x, y, u, v$ be arbitrary points in $X$. We obtain that

$$
\begin{aligned}
d(F(x, y), F(u, v)) & =d\left(\ln \left(1+\frac{x^{2}}{2}+\frac{y^{2}}{2}\right), \ln \left(1+\frac{u^{2}}{2}+\frac{v^{2}}{2}\right)\right) \\
& =\left|\ln \left(1+\frac{x^{2}}{2}+\frac{y^{2}}{2}\right)-\ln \left(1+\frac{u^{2}}{2}+\frac{v^{2}}{2}\right)\right| \\
& =\left|\ln \frac{1+\frac{x^{2}}{2}+\frac{y^{2}}{2} \mid}{1+\frac{u^{2}}{2}+\frac{v^{2}}{2}}\right| \\
& =\left|\ln \left(1+\frac{\left(\frac{x^{2}}{2}+\frac{y^{2}}{2}\right)-\left(\frac{u^{2}}{2}+\frac{v^{2}}{2}\right)}{1+\frac{u^{2}}{2}+\frac{v^{2}}{2}}\right)\right| \\
& \leq \ln \left(1+\left|\left(\frac{x^{2}}{2}+\frac{y^{2}}{2}\right)-\left(\frac{u^{2}}{2}+\frac{v^{2}}{2}\right)\right|\right) \\
& \leq \ln \left(1+\frac{1}{2}\left|x^{2}-u^{2}\right|+\frac{1}{2}\left|y^{2}-v^{2}\right|\right) \\
& =\frac{\ln \left(1+\frac{1}{2}\left|x^{2}-u^{2}\right|+\frac{1}{2}\left|y^{2}-v^{2}\right|\right)}{\left(\frac{1}{2}\left|x^{2}-u^{2}\right|+\frac{1}{2}\left|y^{2}-v^{2}\right|\right)}\left(\frac{1}{2}\left|x^{2}-u^{2}\right|+\frac{1}{2}\left|y^{2}-v^{2}\right|\right) \\
& =\frac{\ln \left(1+\frac{1}{2} d(g x, g u)+\frac{1}{2} d(g y, g v)\right)}{\left(\frac{1}{2} d(g x, g u)+\frac{1}{2} d(g y, g v)\right)}\left(\frac{1}{2} d(g x, g u)+\frac{1}{2} d(g y, g v)\right) \\
& =\theta(d(g x, g u), d(g y, g v))\left(\frac{1}{2} d(g x, g u)+\frac{1}{2} d(g y, g v)\right) \\
& \leq \theta(d(g x, g u), d(g y, g v)) \max \{d(g x, g u), d(g y, g v)\} .
\end{aligned}
$$

This shows that condition (3.1) holds with the function $\theta$.

Next, we check that $g$ and $F$ are compatible. Let $\left\{x_{n}\right\}$ and $\left\{y_{n}\right\}$ be two sequences in $X$ such that

$$
\lim _{n \rightarrow \infty} g x_{n}=\lim _{n \rightarrow \infty} F\left(x_{n}, y_{n}\right)=a \text { and } \lim _{n \rightarrow \infty} g y_{n}=\lim _{n \rightarrow \infty} F\left(y_{n}, x_{n}\right)=b
$$

Then $\ln \left(1+\frac{a}{2}+\frac{b}{2}\right)=a$ and $\ln \left(1+\frac{a}{2}+\frac{b}{2}\right)=b$, wherefrom it follows that $a=b=0$. Then

$$
d\left(g F\left(x_{n}, y_{n}\right), F\left(g x_{n}, g y_{n}\right)\right)=\left|\left(\ln \left(1+\frac{x_{n}^{2}}{2}+\frac{y_{n}^{2}}{2}\right)\right)^{2}-\ln \left(1+\frac{x_{n}^{4}}{2}+\frac{y_{n}^{4}}{2}\right)\right| \rightarrow 0 \quad(n \rightarrow \infty),
$$

and similarly $d\left(g F\left(y_{n}, x_{n}\right), F\left(g y_{n}, g x_{n}\right)\right) \rightarrow 0$. 
We can easily check that all other conditions of Theorem 3.7 hold. Therefore, $g$ and $F$ have a unique common coupled fixed point. In this example, we can see that a point $(0,0) \in X \times X$ is a unique common coupled fixed point of $g$ and $F$.

Remark 3.12 We conclude remarking that the approach used in this paper (i.e., using $g$-monotone instead of $g$-mixed monotone mappings) has the advantage when considering $n$-tupled common fixed points for odd $n$. For example, one can consider mappings $F$ : $X^{3} \rightarrow X$ and $g: X \rightarrow X$ and say that the mapping $F$ is $g$-monotone if $F(x, y, z)$ is $g$-nondecreasing in all three variables, that is, for all $x, y, z \in X$,

$$
\begin{array}{lll}
x_{1}, x_{2} \in X, & g\left(x_{1}\right) \preceq g\left(x_{2}\right) \quad \Rightarrow \quad F\left(x_{1}, y, z\right) \preceq F\left(x_{2}, y, z\right), \\
y_{1}, y_{2} \in X, & g\left(y_{1}\right) \preceq g\left(y_{2}\right) \quad \Rightarrow \quad F\left(x, y_{1}, z\right) \preceq F\left(x, y_{2}, z\right), \\
z_{1}, z_{2} \in X, & g\left(z_{1}\right) \preceq g\left(z_{2}\right) \quad \Rightarrow \quad F\left(x, y, z_{1}\right) \preceq F\left(x, y, z_{2}\right) .
\end{array}
$$

In particular, if $g=I_{X}, F$ is said to be monotone. An element $(x, y, z) \in X^{3}$ is called a tripled coincidence point of $F$ and $g$ if $F(x, y, z)=g x, F(y, z, x)=g y$ and $F(z, x, y)=g z$. Moreover, $(x, y, z)$ is called a tripled common fixed point of $F$ and $g$ if

$$
F(x, y, z)=g x=x, \quad F(y, z, x)=g y=y \quad \text { and } \quad F(z, x, y)=g z=z .
$$

In particular, for $g=I_{X}$, the element $(x, y, z)$ is called a tripled fixed point of $F$.

Results concerning these notions can be found, e.g., in [24]. Such an approach is not possible for mixed monotone mappings when $n=3$ (see [26]).

\section{Open problems}

- In Theorem 3.1, can the set $\{d(g x, g u), d(g y, g v)\}$ be replaced by other sets?

- Can Theorem 3.1 be improved by replacing the control function $\theta$ by other functions?

- Can Theorem 3.1 be extended and generalized replacing condition (3.1) by other conditions?

\section{Competing interests}

The authors declare that they have no competing interests.

\section{Authors' contributions}

The main idea of this paper was proposed by ZK, PK, SR and WS prepared the manuscript initially and performed all the steps of the proofs in this research. All authors read and approved the final manuscript.

\section{Author details}

${ }^{1}$ Faculty of Mathematics, University of Belgrade, Beograd, 11000, Serbia. ${ }^{2}$ Department of Mathematics, Faculty of Science, King Mongkut's University of Technology Thonburi, 126 Pracha Uthit Road, Bang Mod, Thung Khru, Bangkok, 10140, Thailand. ${ }^{3}$ Theoretical and Computational Science Center (TaCS), Science Laboratory Building, Faculty of Science, King Mongkut's University of Technology Thonburi (KMUTT), 126 Pracha Uthit Road, Bang Mod, Thung Khru, Bangkok, 10140, Thailand. ${ }^{4}$ Faculty of Mathematics and Information Technology, Teacher Education, Dong Thap University, Cao Lanh City, Dong Thap Province, Vietnam. ${ }^{5}$ Department of Mathematics and Statistics, Faculty of Science and Technology,

Thammasat University, Rangsit Center, Pathumthani, 12121, Thailand.

\section{Acknowledgements}

The first author is thankful to the Ministry of Education, Science and Technological Development of Serbia, Project No. 174002. The second author was supported by the Higher Education Research Promotion and National Research University Project of Thailand, Office of the Higher Education Commission (NRU) and Theoretical and Computational Science Center (TaCS). The fourth author would like to thank the Thailand Research Fund and Thammasat University under Grant No. TRG5780013 for financial support during the preparation of this manuscript. 


\section{References}

1. Geraghty, M: On contractive mappings. Proc. Am. Math. Soc. 40, 604-608 (1973)

2. Opoitsev, Vl: Heterogenic and combined-concave operators. Sib. Math. J. 16, 781-792 (1975) (in Russian)

3. Opoitsev, VI: Dynamics of collective behavior. III. Heterogenic systems. Autom. Remote Control 36, 111-124 (1975)

4. Guo, D, Lakshmikantham, V: Coupled fixed points of nonlinear operators with applications. Nonlinear Anal. TMA 11, 623-632 (1987)

5. Bhaskar, TG, Lakshmikantham, V: Fixed point theorems in partially ordered metric spaces and applications. Nonlinear Anal. TMA 65, 1379-1393 (2006)

6. Abbas, M, Ali Khan, M, Radenović, S: Common coupled point theorems in cone metric spaces for $w$-compatible mappings. Appl. Math. Comput. 217, 195-202 (2010)

7. Abbas, M, Sintunavarat, W, Kumam, P: Coupled fixed point in partially ordered G-metric spaces. Fixed Point Theory Appl. 2012, 31 (2012)

8. Berinde, $\mathrm{V}$ : Generalized coupled fixed point theorems for mixed monotone mappings in partially ordered metric spaces. Nonlinear Anal. TMA 74, 7347-7355 (2011)

9. Đorić, D, Kadelburg, Z: Coupled fixed point results for mappings without mixed monotone property. Appl. Math. Lett. 25, 1803-1808 (2012)

10. Harjani, J, López, B, Sadarangani, K: Fixed point theorems for mixed monotone operators and applications to integral equations. Nonlinear Anal. TMA 74, 1749-1760 (2011)

11. Hussain, N, Latif, A, Shah, M: Coupled and tripled coincidence point results without compatibility. Fixed Point Theory Appl. 2012, 77 (2012)

12. Lakshmikantham, V, Ćirić, L: Coupled fixed point theorems for nonlinear contractions in partially ordered metric spaces. Nonlinear Anal. TMA 70, 4341-4349 (2009)

13. Petrusel, A, Petrusel, G, Urs, C: Vector-valued metrics, fixed points and coupled fixed points for nonlinear operators. Fixed Point Theory Appl. 2013, 218 (2013)

14. Roldán, A, Martínez-Moreno, J, Roldán, C, Karapinar, E: Some remarks on multidimensional fixed point theorems. Fixed Point Theory 15, 545-558 (2014)

15. Samet, B: Coupled fixed point theorems for a generalized Meir-Keeler contraction in partially ordered metric spaces. Nonlinear Anal. TMA 72, 4508-4517 (2010)

16. Shatanawi, W: Partially ordered metric spaces and coupled fixed point results. Comput. Math. Appl. 60, 2508-2515 (2010)

17. Sintunavarat, W, Cho, YJ, Kumam, P: Coupled fixed point theorems for weak contraction mapping under F-invariant set. Abstr. Appl. Anal. 2012, Article ID 324874 (2012)

18. Sintunavarat, W, Kumam, P: Coupled coincidence and coupled common fixed point theorems in partially ordered metric spaces. Thai J. Math. 10, 551-563 (2012)

19. Radenović, S: Bhaskar-Lakshmikantham type results for monotone mappings in partially ordered metric spaces. Int. J. Nonlinear Anal. Appl. 5(2), 96-103 (2014)

20. Radenović, S: Some coupled coincidence points results of monotone mappings in partially ordered metric spaces. Int. J. Anal. Appl. 5(2), 174-184 (2014)

21. Radenović, S: Coupled fixed point theorems for monotone mappings in partially ordered metric spaces. Kragujev. J. Math. 38, 249-257 (2014)

22. Borcut, M: Tripled fixed point theorems for monotone mappings in partially ordered metric spaces. Carpath. J. Math 28(2), 207-214 (2012)

23. Borcut, M: Tripled coincidence theorems for monotone mappings in partially ordered metric spaces. Creative Math Inform. 21(2), 135-142 (2012)

24. Kadelburg, Z, Radenović, S: Remarks on some M. Borcut's results in partially ordered metric spaces. Vietnam J. Math. (2014, submitted)

25. Choudhury, BS, Kundu, A: A coupled coincidence point result in partially ordered metric spaces for compatible mappings. Nonlinear Anal. TMA 73, 2524-2531 (2010)

26. Roldán, A, Martínez-Moreno, J, Roldán, C: Multidimensional fixed point theorems in partially ordered complete metric spaces. J. Math. Anal. Appl. 396, 536-545 (2012)

\section{Submit your manuscript to a SpringerOpen ${ }^{\ominus}$ journal and benefit from:}

$\checkmark$ Convenient online submission

- Rigorous peer review

- Immediate publication on acceptance

- Open access: articles freely available online

- High visibility within the field

- Retaining the copyright to your article 